\title{
The adoption of green initiatives in logistics service providers - a strategic perspective
}

\section{Karin Isaksson}

Department of Management and Engineering, Institute of Technology, Linköping University, 58183 Linköping, Sweden

Email: karin.isaksson@liu.se

\section{Pietro Evangelista*}

Institute for Research on Innovation and

Services for Development (IRISS),

National Research Council (CNR),

Via G. Sanfelice 8,

80134 Naples, Italy

Email: p.evangelista@iriss.cnr.it

*Corresponding authors

\section{Maria Huge-Brodin}

Department of Management and Engineering, Institute of Technology, Linköping University, 58183 Linköping, Sweden

Email: maria.huge-brodin@liu.se

\section{Heikki Liimatainen}

Transport Research Centre Verne

Tampere University of Technology, Tampere, Finland

e-mail: heikki.liimatainen@tut.fi

\section{Edward Sweeney}

School of Engineering and Applied Science,

Aston University,

Birmingham, B4 7ET, UK

Email: e.sweeney@aston.ac.uk

\begin{abstract}
Logistics service providers (LSPs) have started to transform their operations and strategy to be more effective from a green perspective. One concern that is of particular interest of LSPs is how to create organisational green awareness and translate this into practice in their operations. The purpose of this paper is to investigate the roles of green strategic commitment and organisation in LSPs' adoption of green initiatives. The data for this study were collected through a questionnaire survey, investigating a sample of LSPs operating in the Swedish, Finnish
\end{abstract}


Isaksson K., Evangelista, P., Huge-Brodin, M., Liimatainen, H., Sweeney E.

and Italian markets. From the literature analysis, a set of testable hypotheses was developed. The results indicate that there are relationships between the nature, as well as the scope, of functional involvement and the green strategic priority. The results further suggest that the inclusion of environmental consideration in the overall business strategy is positively related to the involvement and coordination of multiple functions as well as existence of a separate environmental function.

Keywords: Logistics service providers, Environmental sustainability initiatives, Green strategic priority, Functional involvement, Italian, Finnish and Swedish logistics service markets, Questionnaire survey

\section{Introduction}

The creation and management of environmentally sustainable supply chains has become an increasing concern for many businesses, as well as a major focus in logistics research (Zhu et al., 2008). However, most studies on environmental issues have focused on manufacturing sectors and little attention has been paid to service sectors, such as the logistics service industry (Lin and Ho, 2011). The logistics service provision (LSP) sector is highly competitive and dynamic and has undergone significant change in recent years (Langley, Capgemini, 2015). In particular, logistics service providers (LSPs) have assumed a more strategic and pivotal role in the supply chain of which they are part. This has taken place as a result of the shift away from a business model which focussed primarily on the provision of transportation and warehousing services towards a model which provides a range of value-adding services to customers (Zacharia, et 
The adoption of green initiatives in logistics service providers - a strategic perspective al., 2011). These services include, but are not limited to, localisation, late configuration, supply chain design and process integration. In this context, logistics service providers are under pressure to improve their customer relationship management and to further develop their business models, especially in relation to technology and other enablers that are considered points of differentiation (Evangelista, et al., 2013; Large, et al., 2011).

More recently, this evolving strategic development of LSPs has been expanding to incorporate the environmental dimension as another point of differentiation (Maas, et al., 2014). This reflects the fact that the activities of LSPs contribute significantly to the degradation of the natural environment (WEF, 2009; EC, 2014). In this context, governments and institutions internationally have committed to the achievement of ambitious targets in relation to, for example, greenhouse gas (GHG) emissions. For example, the European Union fixed the target of $60 \%$ reduction in greenhouse gas emissions in the transport sector by 2050 with respect to the 1990 level (EC, 2011). A range of abatement measures have been proposed such as converting freight vehicles to sustainable fuels and propulsion systems, and by employing advanced information and communication technologies (ICT) for more efficient logistics management. There is evidence that an increasing number of LSPs have started to adopt greener perspectives and to reconfigure their operations in 
Isaksson K., Evangelista, P., Huge-Brodin, M., Liimatainen, H., Sweeney E.

line with more environmentally sustainable strategic orientations (Lieb and Lieb, 2010). This transformation has the potential to increase the competiveness of LSPs but it simultaneously creates challenges and concerns in terms of how this should be realised. Relevant concerns that are of particular interest for LSPs are the role of, and need for, strategic commitment, as well as the incorporation of environmental aspects into the business system and company strategy (Jumadi and Zailani, 2010; Pieters et al. (2012).

Another challenge relates to the creation of organisational conditions and structures capable of communicating green awareness and the translation of this green awareness into transport and logistics operations (Panayides, 2007; Lin and Ho, 2011). To be able to point to more specific issues relating to how LSPs should approach environmental sustainability issues on a strategic level, there is a need for a wider understanding of today's situation. However, existing mappings tend to be either general and shallow (Wolf and Seuring 2010) or focusing on more tactical and operational matters (Björklund and Martinsen, 2012; Weijers et al., 2012).

The purpose of this paper is to investigate the respective roles of green strategic commitment and organisational issues in LSPs' adoption of green initiatives. 
The adoption of green initiatives in logistics service providers - a strategic perspective

The paper starts with the theoretical framework. It briefly introduces green initiatives in the context of LSPs and presents an analysis of the conditions needed to integrate environmental aspects into the business strategy. There is a particular focus on the issues associated with organisational structure and functional integration in adopting green initiatives. A set of hypotheses are derived from the literature review and tested through a questionnaire survey conducted in three different European countries (Sweden, Finland and Italy). The third section describes the research approach and methodology in some detail, while the fourth section presents the findings emerging from the survey. The paper concludes with a discussion of the findings, further research avenues and managerial implications.

\section{Theoretical framework}

\subsection{Green initiatives among LSPS}

Higher levels of awareness of the environmental sustainability dimension of business and organisational practices have resulted in an increased interest among researchers in green initiatives, especially those related to supply chain management (Chakraborty, 2010; Sarkis et al. 2011). However, the nature of green practices and activities can vary significantly between sectors. In this section a short introduction on how green 
Isaksson K., Evangelista, P., Huge-Brodin, M., Liimatainen, H., Sweeney E.

initiatives are viewed in the context of this paper is provided. In the literature, an explicit definition in the specific context of LSPs is lacking. In this paper, supply chain activities aimed at reducing environmental burdens are referred to by the authors as green initiatives. These include activities that have a positive effect on environmental awareness and directly or indirectly - to the reduction of emissions. Martinsen and HugeBrodin (2014) have grouped green initiatives into "transport-related" measures (e.g. fuels, vehicle technology, mode choice, behavioural aspects, and transport management) and "beyond-transport" initiatives (e.g. logistics system design, choice of partners, environmental management system, emissions and energy data).

While Wolf and Seuring (2010) conclude that greening of logistics is poorly researched and particularly in the logistics service providers, Lin and Ho (2011) stress that much remains to be learned empirically about how organisational and environmental factors influence green practice adoption in the logistics industry. Similarly, a literature review by Isaksson and Björklund (2010) revealed that LSP literature seldom addresses functional co-ordination and internal collaboration either with or without green concerns, something that to a certain extent is also valid for the whole area of green supply chain management (Sarkis et al., 2011). The authors above together underline the need for further research into 
The adoption of green initiatives in logistics service providers - a strategic perspective how and to what extent functional integration is applied in the adoption process of green initiatives, as well as how it affects service development among LSPs.

\subsection{Influence of environmental strategy}

In order to increase the environmental benefits of a company's activities and service offerings, Maxwell et al. (2006) highlighted the need for strategic commitment and integration of sustainable aspects into the company's existing business system and strategy. However, this integration requires new forms of thinking in existing structures and systems (Baumann et al., 2002) and companies will need to have a clear vision, objectives and strategy supported and driven by the top management (Charter and Clark, 2008). An environmental strategy requires integrated thinking at strategic, tactical and operational levels and cooperation between organisational functions (Sarkis, 2006). Furthermore, the skills, knowledge and motivation of individuals can affect the degree to which green issues are considered in firms (Johansson et al., 2007). Successful integration of green concerns into the business strategy will not occur without clear leadership, resource commitment, and active support from the company's top management (Pujari et al., 2003). 
Isaksson K., Evangelista, P., Huge-Brodin, M., Liimatainen, H., Sweeney E.

However, integration of green concerns in the business process can be a major challenge to the existing business culture. Carter and Rogers (2008) stated that many companies implement social and environmental initiatives that are fragmented and disconnected from their overall strategies. Aragon-Correa et al. (2003) stressed that empirical studies should consider the influence of an organisation's general business environment and internal factors on the strategy. The authors further argued that this can explain why some firms continue with reactive strategies while others become more proactive. According to the literature review conducted by Isaksson and Björklund (2010), the benefits of integrating environmental concerns into business management and strategy are barely addressed in the context of the extant LSP literature. Furthermore, Wolf and Seuring (2010) highlight the problem of the lack of explicit strategy in relation to environmental aspects of transportation and assert that many LSPs have no strategy to face the environmental impacts of transport.

The absence of an explicit environmental strategy not only affects the company externally but also internally. This can lead to difficulties in terms of informing employees about the company's green standpoint, as well as how to manage and structure the environmental work within the 
The adoption of green initiatives in logistics service providers - a strategic perspective

company. The above arguments collectively lead to the following hypothesis:

H1: The existence of green concerns in business strategy is positively related to the implementation of green measures among LSPs.

A critical element mentioned in the literature, when it comes to adopting and implementing environmental systems, is management support. Many studies have shown that green supply chain management (GSCM) practices are positively related to management support (e.g. Daily and Huang, 2001; Zhu et al., 2008; Lin and Ho, 2011). In the study of Zhu et al. (2008), management support included support for GSCM ideas and practices from top and middle-level management, as well as cooperation across organisational functions. The findings achieved by Evangelista (2014) indicate that the support of management and the entrepreneur/owner is also considered critical for the implementation of green initiatives by Italian LSPs. The above arguments lead to the following hypothesis:

H2: The existence of green concerns in business strategy is positively related to top management involvement in the adoption and implementation of green initiatives among LSPS. 
Isaksson K., Evangelista, P., Huge-Brodin, M., Liimatainen, H., Sweeney E.

\subsection{Organisational functions involvement}

An important element in order to generate and achieve a sustainable company is the creation of organisational architectures and systems that are capable of capturing, processing and making sense of environmental information (Griffiths and Petrick, 2001). However, Pertusa-Ortega et al. (2010) argue that organisational structure cannot exclusively be regarded as an element of strategic implementation; instead it should be considered as a resource, which can help to improve environmental performance. Griffiths and Petrick (2001) highlighted the need to effectively internalise the environmental information needed within companies, as well as the associated challenges.

From a more general perspective when it comes to implementing logistics service innovation, Daugerthy et al. (2011) stress that as the lines between traditional functional areas blur a greater focus on extensive collaborative interactions among employees is required. In addition, the authors highlight that employee specialisation may not be a good approach to generating new ideas; instead a broad knowledge base is needed. Panayides (2007) suggested that logistics and transportation firms can derive performance improvements through managerial, organisational and inter-organisational capabilities and the author introduces organisational learning as an important parameter that contributes to logistics innovation. 
The adoption of green initiatives in logistics service providers - a strategic perspective

In addition, coordination and communication among different functional units of a firm enhances the ability of the organisation to respond to changes (Daugerthy et al., 1995). This integration can involve interfaces between functions such as purchasing and procurement, material management, production, transportation, distribution, sales and marketing (Sweeney et al., 2015). Isaksson and Huge Brodin (2013) suggest, that a wide engagement across organisational borders be a feature for LSPs adopting green initiatives. The above arguments collectively lead to the following hypothesis:

H3: The existence of green concerns in business strategy is positively related to the involvement and coordination of multiple functions in the adoption and implementation of green initiatives among LSPs.

Many green practices require the collaboration and coordination of different departments and divisions during adoption. Baumann et al. (2002) stressed the importance of functional co-ordination in order to improve the effectiveness of environmental performance. By integration and close communication between different functions and individuals representing different competencies, a more efficient green solution can be reached (Johansson et al., 2007). However, problems may arise with crossdepartment cooperation (Johansson et al., 2007) and changing from a narrow functional orientation to a cross-functional team approach requires a higher level of information sharing and co-ordination (Bertoluci and 
Isaksson K., Evangelista, P., Huge-Brodin, M., Liimatainen, H., Sweeney E.

Millet, 2009). According to Murphy et al. (1995), the organisational unit in the firm having primary responsibility for managing environmental issues is most frequently a specially created unit dealing with such matters as safety, health and environment. Isaksson and Huge-Brodin (2013) have also suggested the existence of a specialised function as one feature among LSPs adopting green initiatives. The above arguments lead to the following hypothesis:

H4: The existence of green concerns in business strategy is positively related to the existence of a specialised environmental function among LSPS.

While cooperation across organisational functions demands top management support, Zhu et al. (2008) do not specify which functions were involved in that cooperation. Lin and Ho (2011) suggest that LSPs need to sustain more organisational support, especially top management support, for employees' green behaviour. The findings of Isaksson and Huge-Brodin (2013) suggest, based on a few case studies, that there can be an either-or relationship between specialisation and cross-functional engagement. This is captured in the final hypothesis:

H5: The existence of specialised environmental functions in companies is negatively related to the involvement of multiple functions in the adoption and implementation of green initiatives among LSPs. 
The adoption of green initiatives in logistics service providers - a strategic perspective

\section{Research approach}

In order to test the above five hypotheses, data were collected using a questionnaire survey, investigating a sample of LSPs operating in the Swedish, Finnish and Italian markets. The authors had good access to sampling frames in these countries. Furthermore, these countries have economies with varying structures and sizes, and with logistics services sectors that reflect this variation. The same questionnaire was used in all three countries and was derived from earlier research that used primarily case-based approaches and literature reviews. Before launching the survey, the questions were discussed with academic experts and pre-tested with potential respondents. The scope of the questionnaire is quite wide ranging from identification of possible green initiatives to factors influencing their adoption (i.e. drivers and barriers), and hence wider than the scope of this paper. In line with the authors' five hypotheses, this paper addresses the existence of green concerns in business strategy, as well as involvement and coordination of different company functions when adopting green transport and supply chain related measures. That part of the questionnaire that addressed firm characteristics and the existence of an environmental strategy were mainly of a classifying character; the questions that addressed the adoption of green initiatives 
Isaksson K., Evangelista, P., Huge-Brodin, M., Liimatainen, H., Sweeney E.

and the nature of functional involvement used a five-point Likert scale, ranging from 1 (totally disagree) to 5 (totally agree).

\subsection{Data sample}

A web-based survey was used in this study. The Swedish respondents were members of Swedish logistics networks (Sveriges Åkeriföretag and Sveriges Transportindustriförbund). The web-link was sent to 590 respondents. By the end of the three-month survey period, and after four reminders had been sent, 74 respondents had completed the questionnaire (i.e. a response rate of $12.5 \%$ ).

In Finland the survey was sent to 2801 hauliers in a Finnish hauliers association (Finnish Transport and Logistics SKAL), with a reminder sent after one week to non-respondents. The survey was closed after two weeks with 152 completed questionnaires (i.e. a response rate of 5.4\%).

The Italian survey was administered to a sample of 780 LSPs. The mailing list was obtained from several sources (partly from the Italian logistics associations and partly from other sources such as the distribution lists of logistics magazines). In order to avoid duplication and inconsistencies each individual record was checked before the beginning of the survey. The survey was live for six months and four reminders were sent out to the sample firms during that period. The total number of usable 
The adoption of green initiatives in logistics service providers - a strategic perspective questionnaires received was 37 (i.e. a response rate of 4.8\%). No specific size of LSP (besides active on the Swedish, Finnish and Italian market) was targeted in the survey, but because of the cooperation with Finnish small hauliers association, the Finnish respondents were mostly smaller companies while the Swedish and Italian respondents were more varying as to size (see Table 1). The authors acknowledge that this imposes some limitations on the way in which the data can be interpreted and generalised to other contexts.

Table 1 Size of the companies included in the sample firms

\begin{tabular}{|c|c|c|c|c|c|c|c|c|c|}
\hline & & & \multicolumn{6}{|c|}{ Annual turnover } & \multirow[b]{2}{*}{ Total } \\
\hline & & & $\begin{array}{c}\text { less than } \\
2 \mathrm{M} €\end{array}$ & $\begin{array}{r}2-10 \\
\mathrm{M} € \\
\end{array}$ & $\begin{array}{c}10-20 \\
\mathrm{M} € \\
\end{array}$ & $\begin{array}{c}20-50 \\
\mathrm{M} € \\
\end{array}$ & $\begin{array}{c}50-100 \\
\mathrm{M} € \\
\end{array}$ & $\begin{array}{c}\text { more than } \\
100 \mathrm{M} €\end{array}$ & \\
\hline \multirow{6}{*}{ Country } & \multirow{2}{*}{ FIN } & Count & 118 & 28 & 2 & 0 & 0 & 1 & 149 \\
\hline & & $\%$ & $79.2 \%$ & $18.8 \%$ & $1.3 \%$ & $0.0 \%$ & $0.0 \%$ & $0.7 \%$ & $100.0 \%$ \\
\hline & \multirow{2}{*}{ SWE } & Count & 2 & 16 & 15 & 14 & 16 & 8 & 71 \\
\hline & & $\%$ & $2.8 \%$ & $22.5 \%$ & $21.1 \%$ & $19.7 \%$ & $22.5 \%$ & $11.3 \%$ & $100.0 \%$ \\
\hline & \multirow{2}{*}{ ITA } & Count & 3 & 9 & 10 & 8 & 1 & 6 & 37 \\
\hline & & $\%$ & $8.1 \%$ & $24.3 \%$ & $27.0 \%$ & $21.6 \%$ & $2.7 \%$ & $16.2 \%$ & $100.0 \%$ \\
\hline \multirow{2}{*}{ Total } & & Count & 123 & 53 & 27 & 22 & 17 & 15 & 257 \\
\hline & & $\%$ & $47.9 \%$ & $20.6 \%$ & $10.5 \%$ & $8.6 \%$ & $6.6 \%$ & $5.8 \%$ & $100.0 \%$ \\
\hline
\end{tabular}

\subsection{Method of analysis}

Data analyses were performed using the SPSS software. Hypotheses testing mainly involved the analysis of nominal variables and was, therefore, carried out principally using cross tabulations. The statistical significance of the differences of variable values was analysed using the 
Isaksson K., Evangelista, P., Huge-Brodin, M., Liimatainen, H., Sweeney E.

Pearson Chi-Square test of independence, which assesses whether paired observations on two variables are independent of each other. For $\mathrm{H} 2$, the other variable (i.e. top management involvement) is an ordinal measure (i.e. a 5 point Likert scale) so a one-way ANOVA (analysis of variance) test was used. Statistical significance was determined at the $\mathrm{p}<0.05$ level.

\section{Main findings and discussion}

This section presents a summary of the survey data and their analysis based on the five hypotheses stated above. In most cases the analysis confirms what might be deemed intuitive, albeit these issues have not been specifically addressed in previous research. The discussion also leads directly to the identification of potentially fruitful areas for future research that will generate deeper and richer insights into the phenomena under investigation (see section 5).

H1. The existence of green concerns in business strategy is positively related to the implementation of green measures among LSPS.

It has been suggested that integrating sustainable aspects into a company's business strategy can lead to improvements in its environmental activities and service offerings (Maxwell et al., 2006). In line with this, the results from the survey support $\mathrm{H} 1$ (see Table 2), indicating that the inclusion of green concerns in the business strategy is positively related to the 
The adoption of green initiatives in logistics service providers - a strategic perspective implementation of environmental measures among LSPs. Regarding the existence of an environmental strategy, Wolf and Seuring (2010) note a lack of such strategies among both LSPs and manufacturing companies. However, the results from our study show that the great majority of LSPs have incorporated green concerns as a part of their overall business strategies, either formally $(89.7 \%)$ or informally $(75.3 \%)$.

Table 2 The relationship between green concerns in business strategy and implementation of green measures

\begin{tabular}{|c|c|c|c|c|c|}
\hline & & & \multicolumn{2}{|c|}{$\begin{array}{l}\text { Company has implemented } \\
\text { environmental measures? }\end{array}$} & \multirow{2}{*}{ Total } \\
\hline & & & yes & no & \\
\hline \multirow{6}{*}{$\begin{array}{l}\text { Incorporation of green concerns } \\
\text { in business strategy? }\end{array}$} & \multirow{2}{*}{ yes formal } & Count & 78 & 9 & 87 \\
\hline & & $\%$ & $89.7 \%$ & $10.3 \%$ & $100.0 \%$ \\
\hline & \multirow{2}{*}{ yes informal } & Count & 70 & 23 & 93 \\
\hline & & $\%$ & $75.3 \%$ & $24.7 \%$ & $100.0 \%$ \\
\hline & \multirow{2}{*}{ no } & Count & 12 & 43 & 55 \\
\hline & & $\%$ & $21.8 \%$ & $78.2 \%$ & $100.0 \%$ \\
\hline \multirow{2}{*}{\multicolumn{2}{|c|}{ Total }} & Count & 160 & 75 & 235 \\
\hline & & $\%$ & $68.1 \%$ & $31.9 \%$ & $100.0 \%$ \\
\hline
\end{tabular}

H2: The existence of green concerns in business strategy is positively related to top management involvement in the adoption and implementation of green initiatives among LSPS.

Support and commitment from top management is often mentioned in the literature as crucial in order to achieve successful integration of green 
Isaksson K., Evangelista, P., Huge-Brodin, M., Liimatainen, H., Sweeney E.

concerns into business strategy (e.g. Charter and Clark, 2008; Pujari et al., 2003). In line with this and supporting H2, our results suggest such a relationship between the incorporation of green concerns into business strategy and top management involvement among LSPs (see Table 3). Whether environmental concern is formally or informally a part of business strategy is seemingly of less importance than a definite lack of environmental concern in the business strategy. All countries show a similar pattern, but the Italian and Swedish companies have higher averages than their Finnish counterparts, due to higher share of companies with green concerns in business strategy. However, active support may not be enough in order to improve environmental performance. Other factors that may have an influence are: new forms of thinking in existing structures and systems (Baumann et al., 2002); clear leadership and resource commitment (Pujari et al., 2003); and, encouraging cross cooperation between organisational function as well as individuals' skills, knowledge and motivation (Johansson et al., 2007). 
Table 3 The relationship between green concerns in business strategy and top management involvement

\begin{tabular}{|l|c|c|c|}
\hline Green concerns in business strategy? & Mean & $\mathrm{N}$ & Std. Deviation \\
\hline yes, formal & 4.32 & 73 & 0.998 \\
yes, informal & 3.95 & 61 & 1.217 \\
no & 2.82 & 11 & 1.779 \\
Total & 4.05 & 145 & 1.221 \\
ANOVA: $\mathrm{F}=8.280 \mathrm{p}=0.000$ & &
\end{tabular}

Top management is actively involved in managing environmental effects (1=totally disagree, 5=totally agree)

H3: The existence of green concerns in business strategy is positively related to the involvement and coordination of multiple functions in the adoption and implementation of green initiatives among LSPS.

Our third hypothesis suggests that the existence of green concerns in business strategy is positively related to the involvement and coordination of multiple functions in environmental work. As shown in Table 4, the results support this for LSPs investigated. In our analysis multiple functions are determined to be involved if the respondent has chosen value 4 (somewhat agree) or 5 (totally agree) to more than one function in the question "The following function is actively involved in managing environmental effects." Charter and Clark (2008) highlight the importance of clear vision, objectives and strategy regarding environmental concerns; 
Isaksson K., Evangelista, P., Huge-Brodin, M., Liimatainen, H., Sweeney E. however in our study the formality dimension does not affect the involvement of functions. This finding is in line with Pertusa-Ortega et al., (2010) who concluded that organisational structure cannot exclusively be regarded as an element of strategic implementation; rather, it should be considered as a resource, which can help to improve environmental performance. Furthermore, there are no significant differences between Finnish and Swedish LSPs, but the Italian LSPs score higher for multiple functions involved in companies with formal green concerns (94\%).

While our results point to a positive relationship between the incorporation of green concerns into strategy and the involvement and coordination of multiple functions, this raises new questions. Does the existence of green concerns in business strategy lead to more functions being involved in the environmental activities, or is it the widespread interest among the employees and cross-functional working that support the incorporation - sometimes formal - of environmental concerns into business strategy? 
Table 4 The relationship between green concerns in business strategy and involvement of multiple functions

\begin{tabular}{|c|c|c|c|c|c|}
\hline & & & \multicolumn{2}{|c|}{$\begin{array}{l}\text { Multiple functions } \\
\text { involved? }\end{array}$} & \multirow[t]{2}{*}{ Total } \\
\hline & & & no & yes & \\
\hline \multirow{6}{*}{$\begin{array}{l}\text { Green concerns } \\
\text { in business } \\
\text { strategy? }\end{array}$} & \multirow{2}{*}{ yes, formal } & Count & 15 & 58 & 73 \\
\hline & & $\%$ & $20.5 \%$ & $79.5 \%$ & $100.0 \%$ \\
\hline & \multirow{2}{*}{ yes, informal } & Count & 16 & 53 & 69 \\
\hline & & $\%$ & $23.2 \%$ & $76.8 \%$ & $100.0 \%$ \\
\hline & \multirow{2}{*}{ no } & Count & 7 & 5 & 12 \\
\hline & & $\%$ & $58.3 \%$ & $41.7 \%$ & $100.0 \%$ \\
\hline \multirow{2}{*}{ Total } & & Count & 38 & 116 & 154 \\
\hline & & $\%$ & $24.7 \%$ & $75.3 \%$ & $100.0 \%$ \\
\hline
\end{tabular}

H4: The existence of green concerns in the business strategy is positively related to the existence of a specialised environmental function among LSPS.

The survey results confirm the fourth hypothesis. They put in evidence that green concerns in the business strategy are positively related to the existence of a specialised environmental function among LSPs. The relationship is strong and also applies across the levels of formality (see Table 5), although the relationship is more evident in the case of formal inclusion. Italian companies, however, have a very low prevalence of specialised environmental functions in companies with informal green concerns in business strategy (11.8\%) compared to Swedish and Finnish 
Isaksson K., Evangelista, P., Huge-Brodin, M., Liimatainen, H., Sweeney E.

companies $(56.0 \%$ and $52.6 \%$, respectively). According to a study by Murphy et al., (1995), the organisational unit in the firm having primary responsibility for managing environmental issues is most frequently a specially created unit. Among the LSPs in our study, there was an equal share of those having and not having a specialised environmental function. Hence, we suggest that the LSPs on a general level lag a bit behind other companies regarding the existence of a specialised environmental function.

Table 5 The relationship between green concerns in business strategy and specialised environmental function.

\begin{tabular}{|c|c|c|c|c|c|}
\hline & & & \multicolumn{2}{|c|}{$\begin{array}{l}\text { Specialised environmental } \\
\text { function? }\end{array}$} & \multirow[t]{2}{*}{ Total } \\
\hline & & & yes & no & \\
\hline \multirow{6}{*}{$\begin{array}{l}\text { Green concerns in } \\
\text { business strategy? }\end{array}$} & \multirow{2}{*}{ yes formal } & Count & 63 & 22 & 85 \\
\hline & & $\%$ & $74.1 \%$ & $25.9 \%$ & $100.0 \%$ \\
\hline & \multirow{2}{*}{ yes informal } & Count & 46 & 54 & 100 \\
\hline & & $\%$ & $46.0 \%$ & $54.0 \%$ & $100.0 \%$ \\
\hline & \multirow{2}{*}{ no } & Count & 9 & 52 & 61 \\
\hline & & $\%$ & $14.8 \%$ & $85.2 \%$ & $100.0 \%$ \\
\hline \multirow{2}{*}{ Total } & & Count & 117 & 127 & 244 \\
\hline & & $\%$ & $48.0 \%$ & $52.0 \%$ & $100.0 \%$ \\
\hline
\end{tabular}

H5: The existence of specialised environmental functions in companies is negatively related to the involvement of multiple functions in the adoption and implementation of green initiatives among LSPS 
The adoption of green initiatives in logistics service providers - a strategic perspective

The analysis reveals that the last hypothesis, which suggests that the existence of specialised environmental functions in companies is in conflict with the involvement of multiple functions when adopting green initiatives among LSPs, cannot be supported. In fact, the existence of a specialised environmental function is positively related to the involvement of multiple functions in the environmental work carried out in LSPs (see Table 6). Thus these results contradict the suggestions by Isaksson \& Huge-Brodin (2013). There are no significant differences between Finnish and Swedish companies. On the other hand, Italian companies are different, because the percentage of firms where multiple functions are involved is the same among companies with as those without specialised environmental functions.

Since many researchers stress the importance of functional coordination in order to improve effectiveness of the environmental performance (e.g. Baumann et al., 2002; Johansson et al., 2007) the relatively large number of LSPs using multiple functions when adopting green initiatives is a promising result. Hence, a useful next step can be to investigate which specific functions are involved and also how LSPs integrate these functions into the process of adopting green initiatives. 
Isaksson K., Evangelista, P., Huge-Brodin, M., Liimatainen, H., Sweeney E.

Table 6 The relationship between green concerns in business strategy and specialised environmental function.

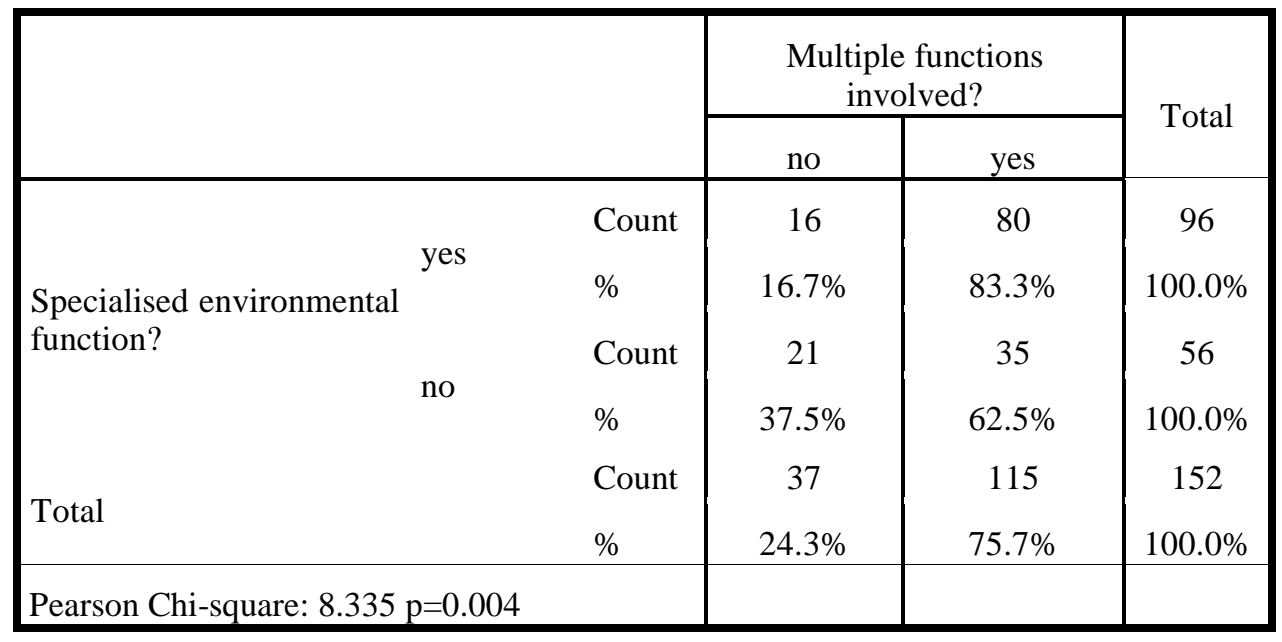

\section{Conclusion}

Their role in the supply chain, as well as their reliance on transport, makes LSPs important players in the greening of logistics systems. Overall, our results clearly indicate that the incorporation of green concerns into the overall strategy formulation processes of LSPs is directly related to the implementation of green initiatives in practice, as well as to the organisation of the associated internal activities. It is also evident that the level of formality regarding the incorporation of green concerns seems to play a lesser role for LSPs than in other sectors (cf. Charter and Clark, 2008). Further, our results suggest that the spread of organisational knowledge and organisational structure are related to each other among LSPs, and that efforts aimed at greening LSPs can take different paths 
The adoption of green initiatives in logistics service providers - a strategic perspective simultaneously. This points to the importance of further studies into the organisation of the environmental work performed by LSPs, in order to find efficient ways for LSPs to organise and structure their work (cf. Isaksson and Huge-Brodin, 2013). This should focus on both internal processes in order to further our understanding of cause-effect relationships, as well as on the organisation of knowledge, organisational learning and the acquisition of green capabilities among LSPs (cf. PetrusaOrtega et al., 2010).

To take the results further there is a need for qualitative case-based research in order to generate deeper and richer insights into internal work activities (e.g. the processes behind the work distribution, individuals' roles and responsibilities, the incorporation of green concerns into business strategy and into product offerings). As noted in section 3 , the results of our research reflect the situation among LSPs in three EU countries with economies of different structures and sizes. Further potentially fruitful research could extend the scope to include more countries, including in contexts other than the European, with presumably different business cultures and different types of legislation framing the business of LSPs. Our initial findings suggest that differences between countries may be explained by differences in LSP industry structures and other factors. 
Isaksson K., Evangelista, P., Huge-Brodin, M., Liimatainen, H., Sweeney E.

But who is responsible for the adoption of green initiatives in LSPs? Strategic presence and top management support are aspects that are clearly related to cross-functional green involvement, as well as to investment in specialised environmental functionality amongst LSPs. The existence of green concern in the overall business strategy can be considered as more or less a prerequisite for green initiatives to be adopted among LSPs. Both formal and informal inclusion of an environmental dimension has a positive effect, but there is - not surprisingly - a general pattern that suggests that formal incorporation strengthens the environmental dimension further. It appears that there is no conflict among LSPs between cross-functional involvement and the existence of specialised functions, which in turn would encourage LSPs to address the green challenge in various ways simultaneously, while still considering how they use their resources most efficiently given each company's specific context.

As noted in the introduction, much of the research to date into environmental issues has focussed on manufacturing sectors with relatively little attention having been paid to service industries such as logistics. This study begins to address this gap. Whilst the LPS sector does have several unique characteristics, it is likely that other service industries can learn from some of the findings of the current study. Another potentially fruitful research avenue would involve the adoption of a 
The adoption of green initiatives in logistics service providers - a strategic perspective

research approach such as that described in this paper in other service sectors along the supply chain.

Finally, in comparison with previous research into green issues in companies in general, as well as among LSPs, our results suggest that LSPs are increasingly including environmental concerns in their business strategies and adopting green initiatives. Based on the existence of a green component in the business strategy, the findings emerging from this study suggest that LSPs have made significant progress over the last few years. Although much remains to be done in the field of environmental sustainability in the logistics service industry, this study suggests that LSPs are adopting green strategies supported by an increasing organisational involvement in relation to green issues and challenges.

\section{References}

Aragon-Correa, J.A. and Sharma, S. (2003) 'A contingent resource-based view of proactive corporate environmental strategy', Academy of Management Review, Vol. 28, No. 1, pp. 71-88.

Baumann, H., Boons, F. and Bragd, A. (2002) 'Mapping the green product development field: engineering, policy and business perspectives', Journal of Cleaner Production, Vol. 10, No. 5, pp. 409-425.

Bertoluci, G. and Millet, D. (2009) 'Functional product enrichment and supply chain disorganisation: two barriers for sustainable design', International Journal of Product Development, Vol. 7, No. 1-2, pp. 149-169.

Carter, C.R. and Rogers, D.S. (2008) 'A framework of sustainable supply chain management: moving toward new theory', International Journal of Physical Distribution \& Logistics Management, Vol. 38, No. 5 , pp. 360-387. 
Isaksson K., Evangelista, P., Huge-Brodin, M., Liimatainen, H., Sweeney E.

Chakraborty, S. (2010) 'Concise Chronological Road Map of Evolving Green Supply Chain Management Concepts: A Review', The IUP Journal of Supply Chain Management, Vol. 7, No. 4, pp. 7-25.

Charter, M. and Clark, T. (2008) 'Product sustainability: organisational considerations', International Journal of Product Development, Vol. 6, No. 3-4, pp. 251-275.

Daugerthy, P.J., Chen, H. and Ferrin, B.G. (2011) 'Organizational structure and logistics service innovation', The International Journal of Logistics Management, Vol. 22, No. 1, pp. 26-51.

Daily, B.F. and Huang, S-C. (2001) 'Achieving sustainability through attention to human resource factors in environmental management', International Journal of Operations and Production Management, Vol. 21, No. 12, pp. 1539-1552.

Evangelista, P. (2014) 'Environmental sustainability practices in the transport and logistics service industry: an exploratory case study investigation', Research in Transportation Business \& Management, Vol. 12, pp. 63-72.

Evangelista, P., McKinnon, A., Sweeney, E., (2013) 'Technology adoption in small and medium-sized logistics providers', Industrial Management \& Data Systems, Vol. 113, No. 7, pp. 967-989.

EC - European Commission (2011) 'White Paper, Roadmap to a Single European Transport Area, Towards a competitive and resource efficient transport system', COM(2011) 144 final, Brussels.

EC - European Commission (2014) 'EU transport in figures. Statistical pocketbook 2014'. Publications Office of the European Union, Luxembourg.

Griffiths, A. and Petrick, J.A. (2001) 'Corporate architectures for sustainability', International Journal of Operations \& Production Management, Vol. 21, No. 12, pp. 1573-1585.

Isaksson, K. and Björklund, M. (2010) 'Developing sustainable logistics services', in Stentoft Arlbjørn, J., (Ed.), The 22 $2^{\text {nd }}$ Annual NOFOMA Conference - Logistics and Supply Chain Management in a Globalised Economy, pp. 985-1000.

Isaksson, K., Huge-Brodin, M. (2013), Understanding efficiencies behind logistics service providers' green offerings. Management Research Review, Vol. 36, No. 3, pp. 216-238.

Johansson, G., Greif, A. and Fleischer, G. (2007) 'Managing the design/environment interface: studies of integration mechanisms', International Journal of Production Research, Vol. 45, No. 18-19, pp. 4041-4055.

Jumadi, H., and Zailani, S. (2010) 'Integrating green innovation in logistics service towards logistics services sustainability: a conceptual paper'. Environmental Research Journal, Vol. 4, No. 4, pp. 261-271. 
Langley, J., Capgemini (2015) '2015 Third-Party Logistics Study. The State of Logistics Outsourcing. Results and Findings of the $19^{\text {th }}$ Annual Study'. Available at: www.3plstudy.com

Large, R.O., Kramer N., Hartmann R.K. (2011) 'Customer-specific adaptation by providers and their perception of 3PL-relationship success'. International Journal of Physical Distribution and Logistics Management. Vol. 41, No. 9, pp. 822-838.

Lieb, K.J., and Lieb, R.C. (2010) 'Environmental sustainability in the third-party logistics (3PL) industry'. International Journal of Physical Distribution and Logistics Management, Vol. 40, No. 7, pp. 524-533.

Lin, C-Y. and Ho, Y-H. (2011) 'Determinants of green practice adoption for logistics companies in China', Journal of Business Ethics, Vol. 98, No. 1, pp. 67-83.

Maas, S., Schuster, T., Hartmann, E. (2014) 'Pollution prevention and service stewardship strategies in the third-party logistics industry: Effects on firm differentiation and the moderating role of environmental communication'. Business Strategy and the Environment, Vol. 23, No. 1, pp. 38-55.

Martinsen, U., Björklund, M. (2012) 'Matches and gaps in the green logistics market', Internatioanl Journal of Physical Distribution and Logistics Management, Vol. 42, No. 6, pp. 562-583.

Martinsen, U., Huge-Brodin, M. (2014) 'Environmental practices as offerings and requirements on the logistics market', Logistics Research, Vol. 7, No. 115, pp. 1-22.

Maxwell, D., Sheate, W. and van der Vorst, R. (2006) 'Functional and systems aspects of the sustainable product and service development approach for industry', Journal of Cleaner Production, Vol. 14, No. 17, pp. 1466-1479.

Murphy, P.R., Poist, R.F. and Braunschweig, C.D. (1995) 'Role and relevance of logistics to corporate environmentalism: an empirical assessment', International Journal of Physical Distribution \& Logistics Management, Vol. 25, No. 2, pp. 5-19.

Panayides, P.M. (2007) 'Effects of organizational learning in third-party logistics', Journal of Business Logistics, Vol. 28, No. 2, pp. 133-158.

Pertusa-Ortega, E.M., Molina-Azorín, J.F. and Claver-Cortés, E. (2010) 'Competitive strategy, structure and firm performance: a comparison of the resource-based view and the contingency approach', Management Decision, Vol. 48, No. 8, pp. 1282-1303.

Pieters, R., Glockner, H.H., Omta, O. and Weijers, S. (2012), 'Dutch logistics service providers and sustainable physical distribution: searching for focus', International Food and Agribusiness Management Review, Vol. 15, pp. 107-126. 
Isaksson K., Evangelista, P., Huge-Brodin, M., Liimatainen, H., Sweeney E.

Pujari, D., Wright, G. and Peattie, K. (2003) 'Influences on environmental new product development performance', Journal of Business Research, Vol. 56, No. 8, pp. 657-671.

Sarkis, J. (2006) 'Greening the supply chain'. Springer.

Sarkis, J., Zhu, Q., Lai, K-H. (2011) 'An organizational theoretic review of green supply chain management literature', International Journal of Production Economics, Vol. 130, No. 1, pp. 1-15.

Sweeney, E., Grant, D.B., John Mangan, J. (2015) 'The implementation of supply chain management theory in practice: an empirical investigation', Supply Chain Management: An International Journal, Vol. 20, No. 1, pp.56-70.

WEF - World Economic Forum (2009) 'Supply chain decarbonisation. The role of logistics and transport in reducing supply chain carbon emissions'. World Economic Forum, Geneva, Switzerland.

Weijers, S., Glöckner, H.H., Pieters, R. (2012) 'Logistic service providers and sustainable physical distribution', Logistikdienstleister und Nachhaltige Distribution, Vol. 8, No. 2, pp. 157-165

Wolf, C. and Seuring, S. (2010) 'Environmental impacts as buying criteria for third party logistics services', International Journal of Physical Distribution \& Logistics Management, Vol. 40, No. 1, pp. 84-102.

Zhu, Q., Sarkis, J., Cordeiro, J.J. and Lai, K-H. (2008) 'Firm-level correlates of emergent green supply in the Chinese context', Omega The International Journal of Management Science, Vol. 36, No. 4, pp. 577-591.

Zacharia, Z.G., Sanders N.R., Nix N.W. (2011) 'The emerging role of the third-party logistics provider (3PL) as an orchestrator'. Journal of Business Logistics, Vol. 32, No. 1, pp. 40-54. 